\title{
Use of a problem-based learning teaching model for undergraduate medical and nursing education: a systematic review and meta-analysis
}

This article was published in the following Dove Press journal:

Advances in Medical Education and Practice

3 October 2017

Number of times this article has been viewed

Mehdi Sayyah'

Kiarash Shirbandi ${ }^{2}$

Amal Saki-Malehi ${ }^{3}$

Fakher Rahim ${ }^{4}$

'Department of Medical Education, Ahvaz Jundishapur of Medical Sciences, Ahvaz, Iran; ${ }^{2}$ Department of Radiology, Allied Health Sciences School, Ahvaz Jundishapur University of Medical Sciences, Ahvaz, Iran; ${ }^{3}$ Department of Biostatistics and Epidemiology, Faculty of Health, Ahvaz Jundishapur University of Medical Sciences, Ahvaz, Iran; ${ }^{4}$ Research Center of Thalassemia and Hemoglobinopathy, Health Research Institute, Ahvaz Jundishapur University of Medical Sciences, Ahvaz, Iran
Correspondence: Fakher Rahim

Research Center of Thalassemia and Hemoglobinopathy, Health Research Institute, Ahvaz Jundishapur University of Medical Sciences, P.O. Box 61537-15794, Ahvaz, Iran

Tel/fax +98 6I 33367652

Email Bioinfo2003@gmail.com
Objectives: The aim of this systematic review and meta-analysis was to evaluate the problembased learning (PBL) method as an alternative to conventional educational methods in Iranian undergraduate medical courses.

Materials and methods: We systematically searched international datasets banks, including PubMed, Scopus, and Embase, and internal resources of banks, including MagirIran, IranMedex, IranDoc, and Scientific Information Database (SID), using appropriate search terms, such as "PBL", "problem-based learning", "based on problems", "active learning", and" learner centered", to identify PBL studies, and these were combined with other key terms such as "medical", "undergraduate", "Iranian", "Islamic Republic of Iran", "I.R. of Iran", and "Iran". The search included the period from 1980 to 2016 with no language limits.

Results: Overall, a total of 1,057 relevant studies were initially found, of which 21 studies were included in the systematic review and meta-analysis. Of the 21 studies, 12 (57.14\%) had a high methodological quality. Considering the pooled effect size data, there was a significant difference in the scores (standardized mean difference $[\mathrm{SMD}]=0.80,95 \% \mathrm{CI}[0.52,1.08], P<0.000$ ) in favor of PBL, compared with the lecture-based method. Subgroup analysis revealed that using $\mathrm{PBL}$ alone is more favorable compared to using a mixed model with other learning methods such as lecture-based learning (LBL).

Conclusion: The results of this systematic review showed that using PBL may have a positive effect on the academic achievement of undergraduate medical courses. The results suggest that teachers and medical education decision makers give more attention on using this method for effective and proper training.

Keywords: problem-based learning, education, meta-analysis, traditional learning

\section{Introduction}

Continuing advances in medical science, technology, and health care delivery have introduced medicine and related fields as a complex, challenging profession. ${ }^{1}$ The efficient medical profession requires advanced and reliable skills such as problem solving and the ability of clinical decision making. ${ }^{2}$ Today, more than ever, most universities in the world try to find teaching methods that can lead to the expansion of the educational capacity, continuous learning, and self-centered clinical decisions among their students. The use of active-learning strategies significantly improves the correlation between the educational and clinical performances of students. ${ }^{3}$ One of the proposed ways to eliminate the gap between academic and clinical performances is changing the traditional educational system to problem-based learning (PBL). PBL was presented as a new teaching method for the first time at McMaster University 
in Canada in the 1960s to enhance the ability of students in independently conducting a study and problem-solving and analytical skills. ${ }^{4}$ If the effectiveness of this method can extend, it may lead to enhanced critical thinking skills and attitudes of undergraduate medical students.

In PBL, the training method is based on the principle of using problems as the starting point; students are divided into several groups and do research on the topic of interest, and the questions are then put to discussion.5 PBL is a student-centered approach, which enables individuals to design, implement, and assess solutions for the problems in their own courses. ${ }^{6}$ Solving a problem as a mental activity increases the level of knowledge and new skills. ${ }^{7}$ Although based on World Health Organization (WHO) data, ${ }^{8}$ PBL is growing worldwide, this model is still controversial. ${ }^{9,10}$

There is growing concern among educators that the conventional educational methods may not lead to the appropriate quality to encourage medical students to learn and impart a lifelong respect for learning. However, Iran has not yet developed a suitable approach to replace the conventional teaching methods. In addition, cultural differences influence the effectiveness of PBL methods, ${ }^{11}$ consequently, the target population must be limited to Iranian medical students of the education system to observe the possible efficacy of the PBL method in Iran. Therefore, the aim of this systematic review and metaanalysis was to evaluate the PBL method as an alternative to conventional educational methods such as lecture-based learning (LBL) method in Iranian undergraduate medical courses.

\section{Materials and methods Iranian medical education capacity}

Medical education in Iran includes 47 medical universities. These 47 universities contain 14 schools of medical sciences, 36 dental schools, 20 pharmacy schools, and 42 nursing schools. These universities include 157,226 students, of whom 29,975 are medical students, 6,966 are pharmacy students, 8,081 are dentistry students, 60,641 are nursing students, and 51, 563 belong to other fields. There are 27 international branches of universities of medical sciences that include 1,341 students. These meta-analysis covers 21 different universities, including $10(10 / 42=23.8 \%)$ nursing schools, eight $(8 / 14=57.2 \%)$ medical schools, and five $(5 / 36=13.8 \%)$ dental schools.

\section{Study design}

This is a systematic review and meta-analysis comparing the use of PBL and LBL teaching models in introductory undergraduate medical courses in Iran and providing a scientific basis for evaluating the need and possibility of PBL application in undergraduate medical courses.

\section{Study selection criteria}

We considered the definition of PBL according to Fan et al. ${ }^{12}$ In short, students schedule to work in small-group activities, make hypotheses about the case of interest and learning subjects, work outside of scheduled hours to meet the learning objectives, and then attempt to solve the problem. The selected studies should fulfill the following criteria, including examination of the PBL application as a teaching method alone or in combination with the traditional LBL teaching model in Iranian medical students, as randomized or non-randomized controlled trials (RCTs). Studies that did not cite the examination data about courses of interest and republished studies were excluded.

\section{Search strategy}

We systematically searched international datasets to identify relevant studies, including PubMed, Scopus, and Embase, and internal resources, including Magiran, IranMedex, IranDoc, and Scientific Information Database (SID) using appropriate search terms, such as "problem-based learning", "PBL", "learning based on problems", "learner centered", and "active learning". These search terms were used to identify studies that used PBL and were combined with other key terms such as "Iranian", "Islamic Republic of Iran", "I.R. of Iran", "Iran", "medical", and "undergraduate". The search included the period from 1980 to 2016 with no language limits. We also manually searched through the reference lists of potentially selected studies to find relevant papers.

\section{Data extraction method and quality assessment}

Screening was done by two reviewers (FR and MS) independently, considering selection criteria; then, the data were extracted and cross-checked. Any inconsistencies were resolved by consultation with a third reviewer (BL). The information including author name, publication year and location, study sample size, participant characteristics, course name and type, study type, intervention process, and outcome scores was extracted. Quality assessments of the selected studies were individually performed by two researchers using the modified Jadad scale that included eight items $^{13}$ and RevMan 5.3 (Cochrane Collaboration, Copenhagen, Denmark). 


\section{Statistical methods}

The outcome measures of interest were a continuous outcome (i.e., examination scores). For the meta-analysis, RevMan version 5.2 and Stata 10.0 (StataCorp LP, College Station, TX, USA) were used. The analytical statistics of standardized mean difference (SMD) at 95\% confidence intervals (CIs) were used to determine the efficacy of the PBL model for outcomes of interest. The method proposed by Zhang et al. ${ }^{14}$ was used to assess the heterogeneity of selected studies; consequently, the $I^{2}$ statistic and the chisquare test were used to assess the statistical heterogeneity of the selected studies. $I^{2}$ value of $>50 \%$ or $P$-value of $<0.10$ was assumed as significant heterogeneity across the included studies. When moderate to high heterogeneity was present, a random-effects model was used to calculate the total SMD score at $95 \% \mathrm{CI}$; otherwise, a fixed-effects model was applied. Meta-regression was used to examine the effect of confounding factors. Subgroup analysis was performed considering teaching patterns, the course type, and the intervention type. To assess the degree of publication bias, we used funnel plots and Egger's tests. A sensitivity analysis was performed by exchanging the combined model (fixed-effects model and random-effects model). We performed subgroup analysis considering three different categories, including the comparison method (PBL vs. LBL or PBL plus LBL vs. LBL), disciplines (nursing, medicine, dentistry, medicine plus dentistry, and other), and grade (freshman, sophomore, junior, senior, and other).

\section{Ethical approval}

This research was approved by the ethics committee of Welfare Organization, Ahvaz, Iran.

\section{Results}

Overall, a total of 1,057 relevant studies were initially found. After the title-abstract screening, 1,034 studies were excluded, and 23 studies were used for the systematic review and meta-analysis. ${ }^{15-37}$ The literature screening process and results are illustrated in Figure 1.

The distributions of available literature across the country are illustrated in Figure 2.

The general characteristics of the included studies are shown in Table 1 . The 23 studies covered four different medical disciplines, including nursing (10 studies), medicine (six studies), dentistry (four studies), and others (three studies). Of the 11 courses examined, including those in anatomy, pharmacology, and biochemistry, only two were laboratory based. $^{27,28}$

The quality of 23 studies was evaluated using the modified Jadad scale. The assessment revealed that only four (17.4\%) studies were assigned scores $>5,,^{18,23,24,34}$ eight (34.8\%) studies were assigned score 5, ${ }^{15-17,25-28,30}$ and 11 (47.8\%) studies

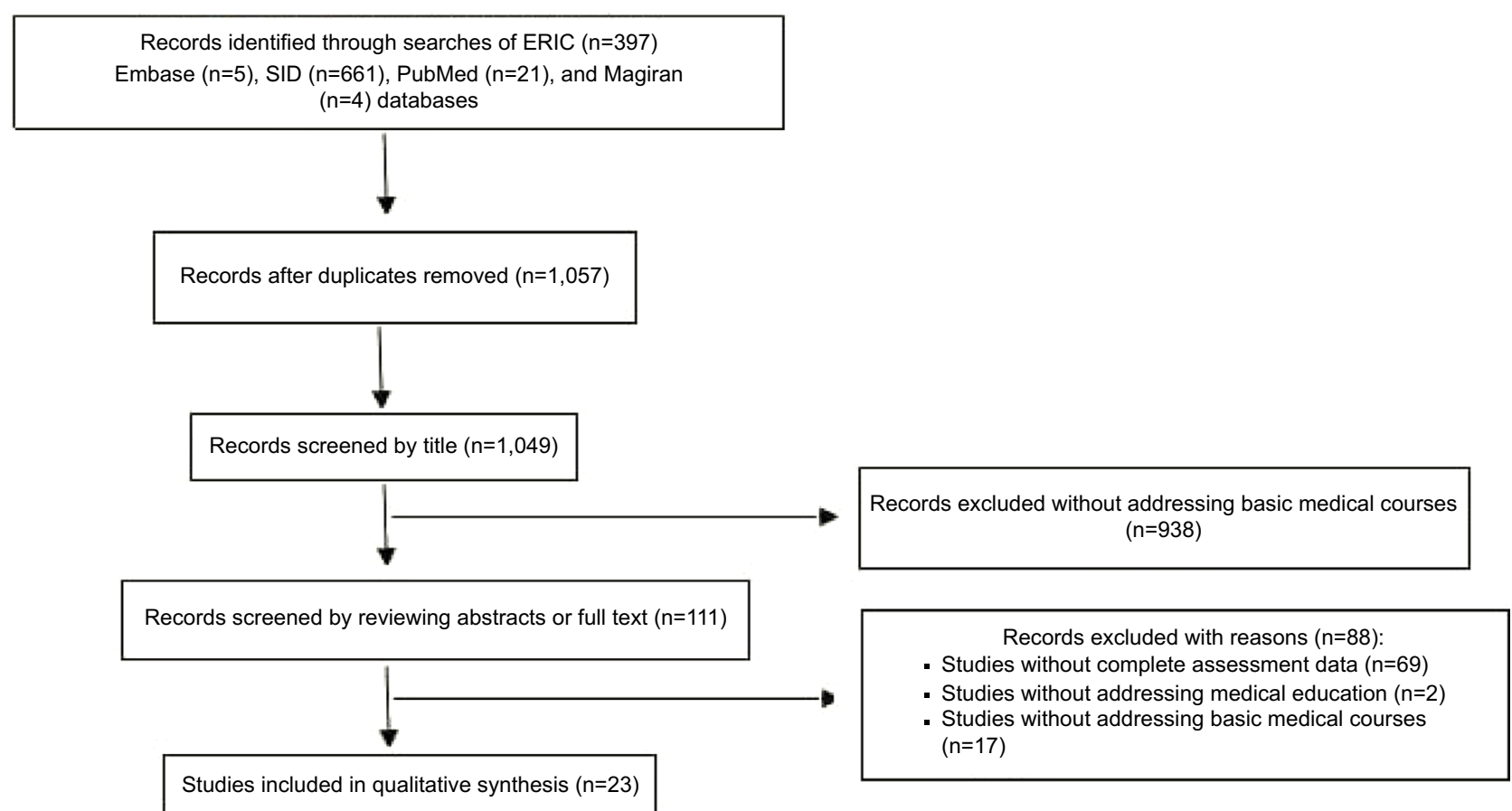

Figure I Literature screening process and results.

Abbreviations: ERIC, Education Resources Information Center; SID, Scientific Information Database. 


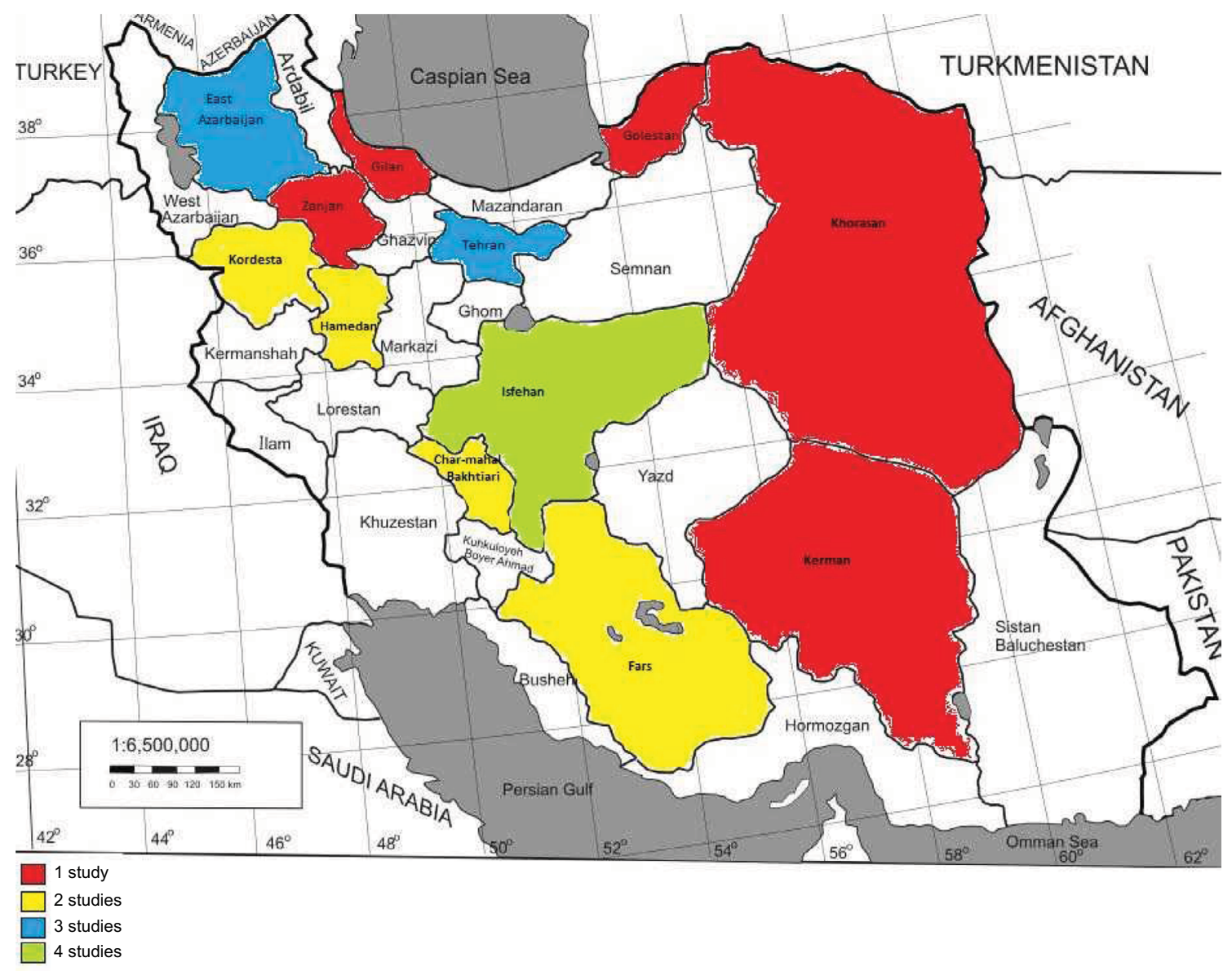

Figure $\mathbf{2}$ The distribution of the available studies across the country.

were assigned scores $2-4^{19-22,29,31-33,35-37}$ (Figure 3). The mean modified Jadad scale score was 4.3, and the standard deviation was 1.25 . The modified Jadad scores collected for each study are shown in the Supplementary materials.

There was high heterogeneity $\left(I^{2}=81 \%, P<0.001\right)$; hence, the random-effects model was used. Considering the pooled effect size data, there was a significant difference in the scores (SMD $=0.80,95 \%$ CI $[0.52,1.08], P<0.000)$ in favor of PBL, compared with the lecture-based method (Figure 4).

Besides, a sensitivity analysis was done to verify the reliability of the results (Supplementary materials). This was performed using sequential omission of individual studies. After excluding a single, ${ }^{17}$ with inadequate generation of a randomized sequence, the effects observed in the primary analysis did not change considering that the pooled effect size favored the PBL group (SMD $=0.72,95 \%$ CI $[0.46,0.97]$, $P<0.000$ ). The funnel plot for the 17 studies was symmetrical, indicating no significant publication bias (Figure 5).

Subgroup analysis considering three different comparison learning methods is shown in Table 2. Subgroup analysis revealed that using PBL alone is more favorable compared to using a mixed model with other learning methods such as LBL (Figure S1). In addition, PBL and LBL learning methods were compared within each stratum, which was specified by various disciplines (i.e., nursing, medicine, dentistry, and other discipline). The result showed that PBL is a more appropriate method in another discipline and an acceptable method in medicine compared to nursing and dentistry (Figure S2). We also compared the SMD for evaluating PBL in five subgroups with respect to various grades. Based on our result, implementation of PBL in sophomore students exhibited a better performance (Figure S3). Finally, subgroup analysis in study subjects (i.e., theory and laboratory) exhibited that PBL is a more proper method in laboratory subjects (Figure S4).

Other discipline that was stated covers the health courses such as occupational health courses. Laboratory courses were newborn and hematology-oncology nursing cares.

\section{Discussion}

This systematic review and meta-analysis aiming to evaluate the PBL method as an alternative to conventional educational methods in Iranian undergraduate medical courses showed 


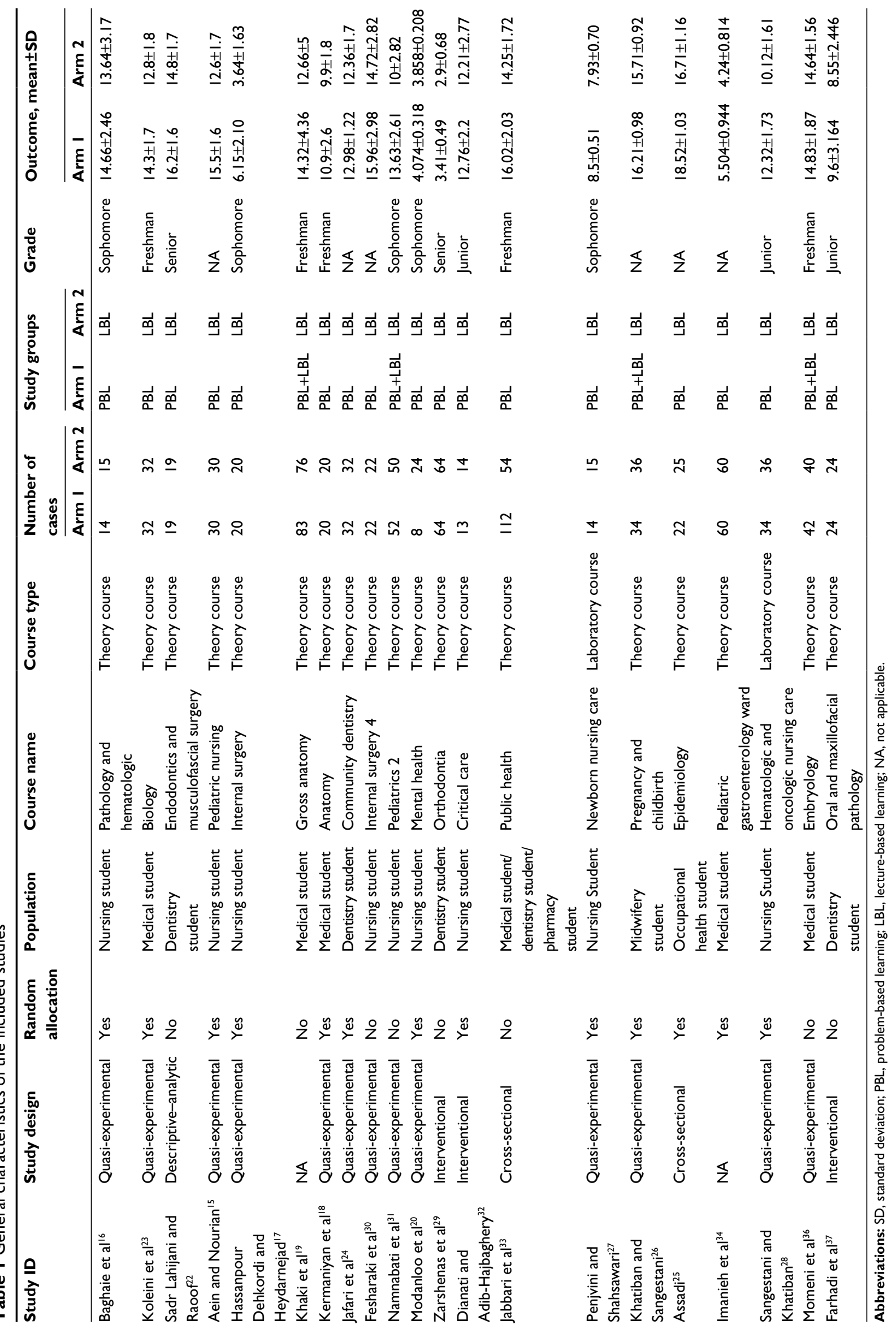




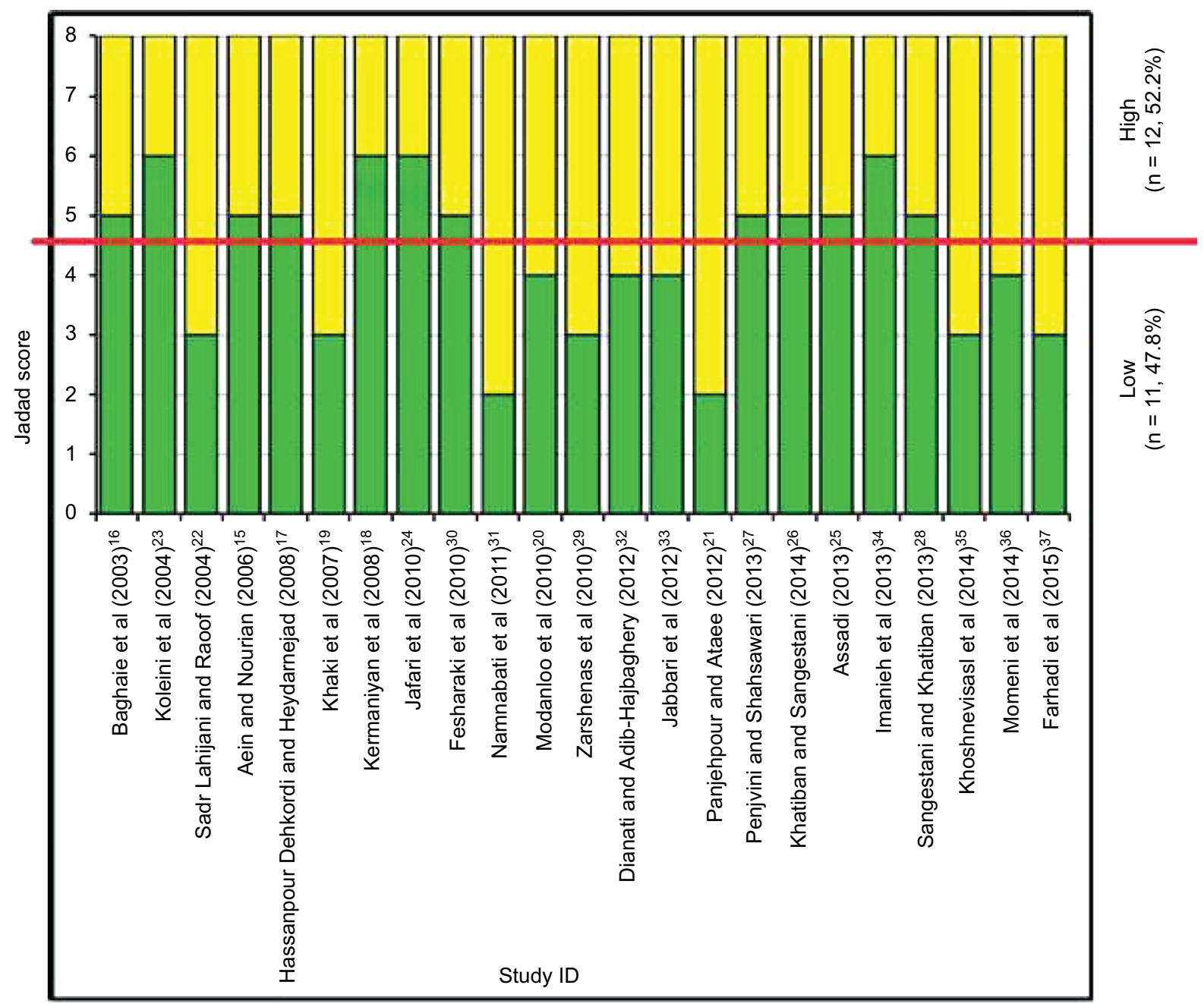

Figure 3 Evaluation of the methodological quality of the included studies.

that academic achievement was relatively higher in PBL method compared to traditional methods such as LBL.

It was shown that the academic achievements of students in the methods such as PBL are significantly higher than those in LBL. ${ }^{38,39}$ Furthermore, the results of a systematic review and meta-analysis in China on dental education showed that the PBL method has a positive effect on theoretical and practical test grades and that introducing this learning method is considered superior to the traditional lecture-based method according to the faculty conditions. ${ }^{40}$ Another systematic review and meta-analysis in Korea on nursing education found that PBL in nursing education has positive effects on the outcome domains of satisfaction with training, clinical education, and skill course; thus, PBL is more effective than traditional learning methods. ${ }^{41}$ Another systematic review and meta-analysis from China on nursing students indicated that PBL might help nursing students to improve their critical thinking. ${ }^{42}$ Our analysis was in line with these meta-analyses and showed that PBL has beneficial effects on the nursing education.

Zhang et al conducted a systematic review and metaanalysis on the PBL use in Chinese undergraduate medical education; this teaching method can rise course examination excellence rates and scores, as well as it is more effective when used in laboratory courses than in theory-based courses. ${ }^{14}$ Though our meta-analysis showed a nonsignificant effect of PBL on medical education, it showed that PBL has positive effects on the outcome domains of laboratory courses compared to theory ones.

In addition, the results of a systematic review and metaanalysis conducted on medical students to evaluate the effect of PBL on the postgraduate physician's abilities showed that PBL has a positive effect on the physician's abilities, particularly on their cognitive abilities and social skills. ${ }^{43}$ Unfortunately, in most medical schools, there is more emphasis on multiple-choice tests as well as the mnemonic and recall 


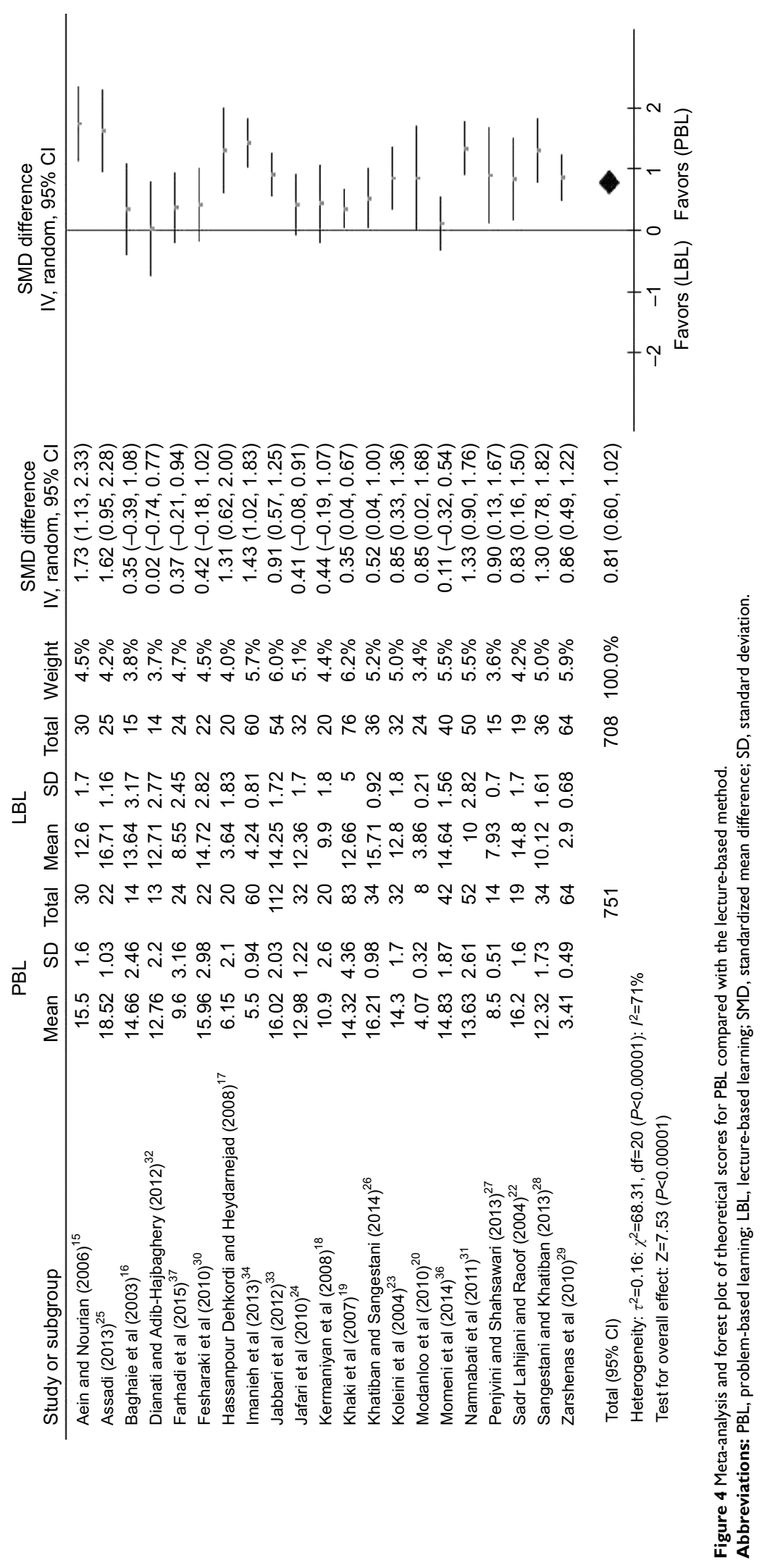


issues learning, although memorization cannot lead to the development of effective problem-solving skills. Besides, the study results were positive in using PBL in all educational levels of students describing the possible effectiveness of this method in undergraduate medical courses.

Recently, Zhou et al ${ }^{44}$ evaluated the effectiveness of PBL in Chinese pharmacy education in a meta-analysis and reported that this teaching method is superior to the traditional lecture-based teaching. We did not find even a single study describing the effect of PBL on pharmacy education compared to traditional learning method.

It was reported that clinical education courses had greater impacts and better outcomes than courses on health perspectives

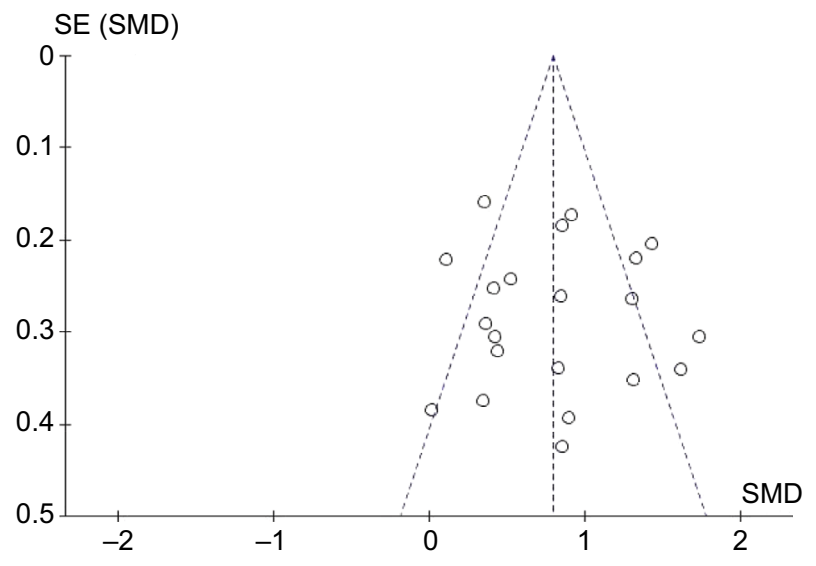

Figure $\mathbf{5}$ The funnel plot for the studies on PBL, compared with the lecture-based method.

Abbreviations: PBL, problem-based learning; SMD, standardized mean difference; SE, standard error. and nursing. Similarly, the clinical approach has larger impact than the theoretical approach. ${ }^{41}$ This supports our findings and previous reports, ${ }^{45,46}$ which found that PBL has a positive effect on medical and nursing students' work-based skills and increases their problem-solving skills. High-level cognitive skills is crucial to develop in clinical practice, which allows students to reach at clinical judgments on the basis of available information when they face unresolved problems, unique cases, ambiguous situations, or cases not present in their textbooks. ${ }^{47}$ PBL is among the techniques considered to be effective in increasing the ability of integrating theory and practice in the students by pursuing and acquiring missing knowledge during clinical practice. ${ }^{48,49}$ Consequently, our findings along with previous evidences may provide educators with evidence that demonstrates the usefulness of PBL in clinical practice.

It is suggested that further experimental studies with regard to standard methods of evaluating and presenting a full report with a complete description of the test interventions in this area to investigate the effects of using PBL are required.

\section{Conclusion}

The results of this systematic review showed that using PBL has a positive effect on the academic achievement of undergraduate medical courses. The results suggest that teachers and medical education decision makers give more attention on using this method for effective and appropriate training. In addition, using suitable methods of evaluation designed for high levels of cognitive tests may encourage students to acquire higher level abilities.

Table 2 Subgroup analysis of selected studies according to various disciplines

\begin{tabular}{|c|c|c|c|c|c|c|c|}
\hline \multirow[t]{2}{*}{ Comparison groups } & \multirow{2}{*}{$\begin{array}{l}\text { No. of } \\
\text { studies }\end{array}$} & \multirow{2}{*}{$\begin{array}{l}\text { Summary estimates of mean } \\
\text { difference }(95 \% \mathrm{Cl})\end{array}$} & \multirow[t]{2}{*}{$I^{2}(\%)$} & \multicolumn{2}{|c|}{ Heterogeneity test } & \multicolumn{2}{|c|}{ Egger's test } \\
\hline & & & & $\bar{Q}$ & $P$ & $t$ & $P$ \\
\hline \multicolumn{8}{|l|}{ Comparison groups } \\
\hline PBL vs LBL & 17 & $0.87(0.65,1.08)$ & 59 & 38.98 & 0.001 & 0.22 & $<0.00001$ \\
\hline $\mathrm{PBL}+\mathrm{LBL}$ vs $\mathrm{LBL}$ & 4 & $0.57(0.07,1.07)$ & 83 & 18.01 & 0.0004 & 0.11 & 0.02 \\
\hline \multicolumn{8}{|l|}{ Discipline } \\
\hline Nursing student & 10 & $0.90(0.56,1.24)$ & 67 & 26.96 & 0.001 & 0.19 & $<0.00001$ \\
\hline Medical student & 5 & $0.64(0.16,1.13)$ & 84 & 24.65 & $<0.0001$ & 0.25 & 0.01 \\
\hline Dentistry student & 4 & $0.66(0.25,1.08)$ & 10 & 3.34 & 0.34 & 0.01 & $<0.00001$ \\
\hline Other & 2 & $1.20(0.52,1.88)$ & 71 & 3.42 & 0.06 & 0.18 & 0.0005 \\
\hline \multicolumn{8}{|l|}{ Grade } \\
\hline Freshman & 5 & $0.53(0.22,0.85)$ & 64 & 11.20 & 0.02 & 0.08 & 0.001 \\
\hline Sophomore & 5 & $1.01(0.65,1.38)$ & 33 & 5.99 & 0.20 & 0.06 & $<0.00001$ \\
\hline Junior & 3 & $0.59(-0.18,1.36)$ & 79 & 9.64 & 0.008 & 0.36 & 0.13 \\
\hline Senior & 2 & $0.85(0.53,1.17)$ & 0 & 0.00 & 0.95 & 0 & $<0.00001$ \\
\hline Other & 6 & $\mathrm{I} .0 \mathrm{I}(0.52, \mathrm{I} .50)$ & 81 & 26.23 & $<0.0001$ & 0.3 & $<0.00001$ \\
\hline \multicolumn{8}{|l|}{ Theory vs laboratory } \\
\hline Theory & 19 & $0.77(0.55,1.0)$ & 72 & 26.23 & $<0.0001$ & 0.17 & $<0.00001$ \\
\hline Laboratory & 2 & $1.18(0.75,1.61)$ & 71 & 0.73 & 0.39 & 0.00 & $<0.00001$ \\
\hline
\end{tabular}

Abbreviations: PBL, problem-based learning; LBL, lecture-based learning. 


\section{Acknowledgment}

This research was the result of a project affiliated by Deputy of Research Affairs, Ahvaz Jundishapur University of Medical Sciences. The abstract of this paper was presented at the 18 Conference of Medical Education in Iran 2017 as a poster presentation/conference talk with interim findings.

\section{Disclosure}

The authors report no conflicts of interest in this work.

\section{References}

1. Institute of Medicine (US) Committee on the Health Professions Education Summit. Challenges facing the health system and implications for educational reform. In: Greiner AC, Knebel E, editors. Health Professions Education: A Bridge to Quality. Washington, DC: National Academies Press (US); 2003:192.

2. MacKinnon K, Marcellus L, Rivers J, Gordon C, Ryan M, Butcher D. Student and educator experiences of maternal-child simulation-based learning: a systematic review of qualitative evidence protocol. JBI Database System Rev Implement Rep. 2015;13(1):14-26.

3. Lucas KH, Testman JA, Hoyland MN, Kimble AM, Euler ML. Correlation between active-learning coursework and student retention of core content during advanced pharmacy practice experiences. Am J Pharm Educ. 2013;77(8):171.

4. Servant VF, Schmidt HG. Revisiting 'Foundations of problem-based learning: some explanatory notes'. Med Educ. 2016;50(7):698-701.

5. Puri D. An integrated problem-based curriculum for biochemistry teaching in medical sciences. IJCB. 2002;17(2):52-59.

6. Yuan H, Kunaviktikul W, Klunklin A, Williams BA. Improvement of nursing students' critical thinking skills through problem-based learning in the People's Republic of China: A quasi-experimental study. Nurs Health Sci. 2008;10(1):70-76.

7. Sherwood AL. Problem-based learning in management education: a framework for designing context. J Manage Educ. 2004;28(5):536-557.

8. Yang L, Xin F. On PBL teaching model in Chinese medical education. J Liaoning Med Univ. 2007;1:010.

9. Farrow R, Norman G. The effectiveness of PBL: the debate continues. Is meta-analysis helpful? Med Educ. 2003;37(12):1131-1132.

10. Schmidt HG, Cohen-Schotanus J, Arends LR. Impact of problem-based, active learning on graduation rates for 10 generations of Dutch medical students. Med Educ. 2009;43(3):211-218.

11. Frambach JM, Driessen EW, Chan LC, van der Vleuten CP. Rethinking the globalisation of problem-based learning: how culture challenges self-directed learning. Med Educ. 2012;46(8):738-747.

12. Fan AP, Kosik RO, Tsai TC, et al. A snapshot of the status of problembased learning (PBL) in Chinese medical schools. Med Teach 2014;36(7):615-620.

13. Oremus M, Wolfson C, Perrault A, Demers L, Momoli F, Moride Y. Interrater reliability of the modified Jadad quality scale for systematic reviews of Alzheimer's disease drug trials. Dement Geriatr Cogn Disord. 2001;12(3):232-236.

14. Zhang Y, Zhou L, Liu X, et al. The effectiveness of the problem-based learning teaching model for use in introductory Chinese undergraduate medical courses: a systematic review and meta-analysis. PLoS One. 2015;10(3): 0120884.

15. Aein F, Nourian K. Problem-based learning: a new experience in education of pediatric nursing course to nursing students. J Shahrekord Univ Med Sci. 2006;8(2):16-20.

16. Baghaie M, Atrkar Roushan Z. A comparison of two teaching strategies: lecture and $\mathrm{PBL}$, on learning and retaining in nursing students. J Guilan Univ Med Sci. 2003;12(47):86-94.
17. Hassanpour Dehkordi A, Heydarnejad M. The effects of problem-based learning and lecturing on the development of Iranian nursing students' critical thinking. Pak J Med Sci. 2008;24(5):740-743.

18. Kermaniyan F, Mehdizadeh M, Iravani S, Markazi Moghadam N, Shayan S. Comparing lecture and problem-based learning methods in teaching limb anatomy to first year medical students. Iran J Med Educ. 2008;7(2):379-388.

19. Khaki AA, Tubbs RS, Zarrintan S, et al. The first year medical students' perception of and satisfaction from problem-based learning compared to traditional teaching in gross anatomy: introducing problem-based anatomy into a traditional curriculum in Iran. Int J Health Sci. 2007;1(1):113.

20. Modanloo M, Khoddam H, Kolagaree S, Bastani F, Parvizi S, Abdollahi $\mathrm{H}$. The effect of problem-based learning on nursing students' learning level. Strides Dev Med Educ. 2010;7(1):17-25.

21. Panjehpour M, Ataee N. Comparison the effectiveness of problem solving method with lecture-based method in the teaching of metabolic biochemistry. Iran J Med Educ. 2012;11(9):1318-1325.

22. Sadr Lahijani M, Raoof K. The effect of PBL and film showing, frequent quizzes and lecture-based method on short-term performance of dentistry students. $J$ Med Educ. 2004;4(2):7-80.

23. Koleini N, Farshidfar F, Shams B, Salehi M. Problem based learning or lecture, a new method of teaching biology to first year medical students: an experience. Iran J Med Educ. 2003;3(2):57-63.

24. Jafari A, Khami M, Yazdani R, Mohamadi M. Presenting the course of community dentistry as problem based learning workshop and comparing it to learning through lecture. Iran J Med Educ. 2010;9(3):216-224.

25. Assadi SN. Comparing the influence of three educational methods on the epidemiology of occupational diseases' learning qualities. Future Med Educ J. 2013;3(4):15-19.

26. Khatiban M, Sangestani G. The effects of using problem-based learning in the clinical nursing education on the students' outcomes in Iran: a quasi-experimental study. Nurse Educ Pract. 2014;14(6):698-703.

27. Penjvini S, Shahsawari S. Comparing problem based learning with lecture based learning on medicine giving skill to newborn in nursing students. J Nurs Educ Prac. 2013;3(9):53.

28. Sangestani G, Khatiban M. Comparison of problem-based learning and lecture-based learning in midwifery. Nurse Educ Today. 2013;33(8):791-795.

29. Zarshenas L, Momeni Danaei S, Oshagh M, Salehi P. Problem based learning: an experience of a new educational method in dentistry. Iran J Med Educ. 2010;10(2):171-179.

30. Fesharaki M, Islami M, Moghimian M, Azarbarzin M. The effect of lecture in comparison with lecture and problem based learning on nursing students self-efficacy in Najafabad Islamic Azad University. Iran J Med Educ. 2010;10(3):262-268.

31. Namnabati M, Fathi Azar E, Valizadeh S, Tazakori Z. Lecturing or problem-based learning: comparing effects of the two teaching methods in academic achievement and knowledge retention in pediatrics course for nursing students. Iran J Med Educ. 2011;10(4):474-482.

32. Dianati M, Adib-Hajbaghery M. Comparison of lecture and problembased learning on learning of nursing students. Future Med Educ J. 2012;2(1):7-11.

33. Jabbari H, Bakhshian F, Alizadeh M, Alikhah H, Naghavi Behzad M. Lecture-based versus problem-based learning methods in public health course for medical students. Res Dev Med Educ. 2012;1(2):31-35.

34. Imanieh M, Dehghani S, Sobhani A, Haghighat M. Evaluation of problem-based learning in medical students' education. $J$ Adv Med Educ Prof. 2013;2(1):1-5.

35. Khoshnevisasl P, Sadeghzadeh M, Mazloomzadeh S, Hashemi Feshareki $\mathrm{R}$, Ahmadiafshar A. Comparison of problem-based learning with lecture-based learning. Iran Red Crescent Med J. 2014;16(5):e5186.

36. Momeni S, Abdolmaleki M, Zarezadeh Y, Rezaie M. Effects of problem based learning approach on medical students' learning, satisfaction and engagement in embryology course. Future Med Educ J. 2014;4(1):27-31. 
37. Farhadi S, Jahanbani J, Kakui Nejad M, Bashiri S. The view point of dentistry students to achievement of educational objectives: comparison of teacher-oriented and problem-based learning methods. J Adv Med Educ. 2015;1(1):22-27.

38. Michel MC, Bischoff A, Jakobs KH. Comparison of problem-and lecture-based pharmacology teaching. Trends Pharmacol Sci. 2002;23(4): $168-170$.

39. Li J, Li QL, Li J, et al. Comparison of three problem-based learning conditions (real patients, digital and paper) with lecture-based learning in a dermatology course: a prospective randomized study from China. Med Teach. 2013;35(2):e963-e970.

40. Huang B, Zheng L, Li C, Li L, Yu H. Effectiveness of problem-based learning in Chinese dental education: a meta-analysis. J Dent Educ. 2013;77(3):377-383.

41. Shin IS, Kim JH. The effect of problem-based learning in nursing education: a meta-analysis. Adv Health Sci Educ Theory Pract. 2013;18(5): 1103-1120.

42. Kong LN, Qin B, Zhou YQ, Mou SY, Gao HM. The effectiveness of problem-based learning on development of nursing students' critical thinking: a systematic review and meta-analysis. Int JNurs Stud. 2014;51(3):458-469.
43. Koh GC, Khoo HE, Wong ML, Koh D. The effects of problem-based learning during medical school on physician competency: a systematic review. CMAJ. 2008;178(1):34-41.

44. Zhou J, Zhou S, Huang C, et al. Effectiveness of problem-based learning in Chinese pharmacy education: a meta-analysis. BMC Med Educ. 2016; $16: 23$.

45. Albanese M. Problem-based learning: why curricula are likely to show little effect on knowledge and clinical skills. Med Educ. 2000;34(9): 729-738.

46. Murphy JI. Using focused reflection and articulation to promote clinical reasoning: an evidence-based teaching strategy. Nurs Educ Perspect. 2004;25(5):226-231.

47. Walker SE. Active learning strategies to promote critical thinking. J Athl Train. 2003;38(3):263-267.

48. Forbes H, Duke M, Prosser M. Students' perceptions of learning outcomes from group-based, problem-based teaching and learning activities. Adv Health Sci Educ Theory Pract. 2001;6(3):205-217.

49. Barrows H. Is it truly possible to have such a thing as dPBL? Dist Educ. 2002;23(1):119-122.
Advances in Medical Education and Practice

\section{Publish your work in this journal}

Advances in Medical Education and Practice is an international, peerreviewed, open access journal that aims to present and publish research on Medical Education covering medical, dental, nursing and allied health care professional education. The journal covers undergraduate education, postgraduate training and continuing medical education

\section{Dovepress}

including emerging trends and innovative models linking education, research, and health care services. The manuscript management system is completely online and includes a very quick and fair peer-review system. Visit http://www.dovepress.com/testimonials.php to read real quotes from published authors.

Submit your manuscript here: http://www.dovepress.com/advances-in-medical-education-and-practice-journal 